\title{
O darwinismo e o sagrado na segunda metade do século XIX: alguns aspectos ideológicos e metafísicos do debate ${ }^{1}$
}

\author{
Darwinism and "the sacred" during the second half of the $19^{\text {th }}$ \\ century: some ideological and metaphysical features of the debate
}

Juanma Sánchez Arteaga*

\section{RESUMO}

$\mathrm{O}$ artigo analisa alguns aspectos ideológicos e metafísicos da transformação do imaginário ocidental sobre a origem da espécie humana - a velha questão, "quem somos?", respondida de formas diversas pelo cristianismo e pela biologia evolutiva - na segunda metade do século XIX. Nesse período passa-se do predomínio da antropogênese cristã ao das explicações evolucionistas. Analisase a confrontação histórica que teve lugar, nesse período, entre alguns dos principais defensores científicos do evolucionismo materialista - Haeckel, Clémence Royer e Huxley - e os defensores de uma antropologia anti-evolucionista e cristã. Analisam-se brevemente os pontos principais da crítica de Darwin à religião e algumas similitudes e discrepâncias de sua crítica ao pensamento religioso com relação à realizada por Marx no mesmo período. Determinados aspectos ideológico-metafísicos foram componentes essenciais do discurso darwinista na sua luta para se impor às narrativas do cristianismo sobre a origem do ser humano.

Palavras-chave: darwinismo; evolução humana; criacionismo.

\section{Abstract}

This paper analyzes some of the ideological and metaphysical features of the historical transformation of Western imaginary on human origins, during the second half of $19^{\text {th }}$ Century. In this period, predominance of the Christian Natural Theology accounts about anthropogenesis gave place to a new paradigm, based on evolutionary biological explanations. We thus analyze the historical confrontation that took place between prominent materialistic scientists - Haeckel, Royer, Huxley - defending evolutionary theories, on one hand, and advocates of a non-evolutionist anthropology linked to Christian believe in Creation, on the other. This paper analyzes the main features of Darwin's criticism of religious thought, based on naturalistic basis, and presents some similarities and differences with the critique of religion made by Marx in the same period. Darwinism included some metaphysical and ideological elements as essential parts of the evolutionary opposition to the old Christian narratives of anthropogenesis.

Keywords: darwinism; human evolution; creationism.

\footnotetext{
* Centro de Ciencias Humanas y Sociales - GEA. Instituto de Historia. Consejo Superior de Investigaciones Científicas (CSIC) - c/ Albasanz, 26-28. Despacho 2E35. 28037 - Madrid España. juanma.sanchez.arteaga@gmail.com.
} 


\section{A TRANSFORMAÇÃO DO IMAGINÁRIO OCIDENTAL SOBRE A ORIGEM BIOLÓGICA DA ESPÉCIE HUMANA (1859-1900)}

Até a segunda metade do século XVIII, a narração da origem de nossa espécie esteve monopolizada em Europa pelo pensamento religioso, e toda a mitologia européia sobre os acontecimentos humanos originais se fundamentou no livro do Gênesis. Mesmo assim, entre os séculos XVII e XVIII, a ideologia burguesa do progresso - que se estendeu de forma explosiva com o auge da Ilustração - , foi encontrando cada vez mais dificuldades em ajustarse aos mitos de origem cristãos.

Com a vertiginosa ascensão da nova classe social hegemônica no Ocidente, o começo da industrialização e o início do desenvolvimento da economia européia para um capitalismo de caráter global, o imaginário coletivo ocidental a respeito da natureza humana começou a sofrer uma profunda transformação de enormes conseqüências históricas. A partir dos séculos XVII e XVIII, os grandes Estados ocidentais passaram a confiar cada vez mais nas ciências para a exploração em grande escala da natureza - por meio da física, geologia, zootecnia, por exemplo - e das pessoas - com o uso da estatística, da medicina e da engenharia militar, entre outras. Deste modo, todo um leque de novas instituições científicas pôde adquirir rapidamente um elevado status social, como organismos produtores do conhecimento correto do ponto de vista oficial, e em lento detrimento da teologia natural e das instituições controladas pela Igreja. Desta forma, se até o século XVIII, as esferas culturais em que se manifestava a ideologia eram, principalmente, as da família e do direito, a política, a ética, a arte e a religião, a partir desse período esta última se vê suplantada muito paulatinamente pela esfera científica ${ }^{2}$ que, pouco a pouco, passa a situar-se na base central da ideologia das sociedades

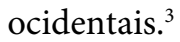

Entre a parte final do século XVIII e o início do século XIX, o transformismo - mais tarde conhecido como evolucionismo - começou a implantarse como uma espécie de alternativa científica à narração bíblica sobre as origens entre um número muito reduzido de pessoas eruditas de ideologia avançada. Depois, durante todo o século XIX, o controle ideológico das Igrejas cristãs sobre as instituições de produção do conhecimento - desde as escolas infantis às cátedras universitárias - continuou notável, ainda que decrescente, em toda a Europa. Apesar do ponto de inflexão associado à publicação da Origem das espécies em 1859, o pensamento cristão se manteve enraizado na cultura européia oitocentista, de modo que as recentes teorias 
evolucionistas não obtiveram uma vitória fácil e rápida em sua nova formulação científica dos acontecimentos fundacionais. Na realidade, durante todo o século XIX o debate biológico em torno da origem natural do ser humano ficou marcado profundamente, com diferentes graus nos diversos países, por uma confrontação meta-empírica - bem mais emocional e ideológica que racional - entre o evolucionismo materialista e progressista das ciências naturais e a antropogenia degeneracionista e dualista (dualismo alma versus corpo humano) defendida pela religião cristã.

Essa situação de choque de paradigmas teóricos, em que dois sistemas simbólicos em luta pelo controle do imaginário coletivo a respeito das origens buscavam assentar sua posição institucional na agitada sociedade européia finissecular, deixou sua marca até mesmo nos títulos das primeiras obras científicas sobre a origem biológica de nossa espécie. Assim, por exemplo, o título da Antiguidade do homem, de Lyell, ${ }^{4}$ refere-se implicitamente à obsoleta cronologia cristã, que datava a criação de nossa espécie em cerca de cinco ou seis mil anos atrás. ${ }^{5}$ Por sua vez, as famosas Lições sobre o homem, de Karl Vogt, ${ }^{6}$ pretendiam explicitar, segundo seu título completo, o verdadeiro lugar na Criação para o ser humano, diante do que lhe atribuía a religião. Haeckel empreendeu a escritura de uma nova História da Criação, que se converteria na Bíblia materialista dos evolucionistas mais fervorosos. ${ }^{7}$ Büchner, no título completo do Homem segundo a ciência, prometia ao leitor uma resposta científica às mesmas perguntas que propunha o Gênesis: "De onde vimos? Quem somos? Aonde vamos?" ${ }^{8}$ E Huxley escreveu "Os intérpretes do Gênesis e os intérpretes da Natureza”, na popular revista The nineteenth century, com o propósito fundamental de negar qualquer tipo de compromisso entre a ordem de sucessão de faunas do Gênesis e os firmes achados da geologia e da paleontologia modernas. ${ }^{9}$

\section{A METAFÍSICA MONISTA NA ANTROPOLOGIA CIENTÍFICA DO SÉCULO XIX: CRÍTICA À ANTROPOLOGIA CRISTÃ}

Na segunda metade do século XIX, a filosofia monista se desenvolveu como uma espécie de metafísica geral do ser humano, que pretendia unir os princípios da filosofia e das ciências naturais sobre as mesmas bases que unificavam a energia e a matéria no cosmos. Por estranho que pareça, essa ambiciosa corrente de pensamento teve enorme influência entre os cientistas e os antropólogos materialistas mais avançados do momento. Diante do velho $d u$ - 
alismo cristão-cartesiano - que dividia a realidade em matéria e espírito como dois elementos diametralmente contrapostos na natureza da humanidade —, o monismo materialista do século XIX concebia força (energia) e matéria como manifestações complementares de um único princípio organizador do universo e, com ele, da vida humana e da ordem das sociedades.

No final do século, a metafísica monista se tinha convertido num verdadeiro credo para boa parte dos antropólogos materialistas mais entusiastas. Büchner, por exemplo, cuja Força e matéria era considerada quase como uma opera sacra para os monistas, proclamava que, "sem dúvida, este sistema [filosófico] supera a todos os demais, a todas as concepções idealistas do mundo, pelo fato de que incorpora o mundo ideal dentro de nós ... Nenhuma outra filosofia já esteve tão intimamente unida à vida" (Büchner, 1872, p.396-397).

Por sua vez, Haeckel partia da idéia de que o espírito não era mais que um simples epifenômeno da atividade da matéria nervosa, para afirmar que, de maneira geral, é impossível aceitar a distinção tão comum entre natureza e espírito: "Existe um espírito em toda a natureza, e um espírito fora da natureza é inconcebível. Em conseqüência, não se pode aceitar de maneira alguma a distinção ordinária entre ciências naturais e ciências do espírito. Toda ciência é, essencialmente, natural e espiritual" (Haeckel, 1877, p.623).

Assim, muitos desses primeiros antropólogos evolucionistas podiam sustentar que as ciências sociais e as ciências empíricas deviam apoiar-se sobre os mesmos fundamentos axiomáticos. Se o social e o natural estavam regidos pelas mesmas diretrizes universais, podia legitimar-se uma extrapolação absoluta dos princípios de organização da natureza para o funcionamento das comunidades humanas. E vice-versa, as leis biológicas da evolução humana podiam adotar-se como princípios de uma organização social racional ou, por assim dizer, baseada em princípios científico-naturais. A extensão dos princípios burgueses da organização social para o âmbito da natureza e das ciências humanas (exemplificada de forma paradigmática na monumental obra de Herbert Spencer $)^{10}$ foi interpretada como confirmação das premissas ontológicas do monismo e do materialismo científico.

Nesse sentido, Paolo Mantegazza - presidente da Sociedade Italiana de Antropologia e um dos antropólogos europeus mais influentes da segunda metade do século XIX - sustentava que, no âmbito acadêmico, assistia-se, naqueles anos, "a uma aproximação contínua de ciências que pareciam antes longínquas e desunidas". ${ }^{11}$ A física e a química nos ensinaram a impossibilidade do vácuo, e, de acordo com esse autor, a filosofia monista, apoiada na ob- 
servação e na experiência (Mantegazza, 1898, p.243-254), tinha exposto a continuidade progressiva das formas e das energias no cosmos e nas sociedades:

E se hoje chamamos organismos às sociedades, e dizemos que umas e outros são agregações de células ... é porque estamos persuadidos de que na Natureza tudo se toca, que não existe nada isolado e independente no mundo; de que as afinidades eletivas, que com tanta temperatura e luz atraem o potássio ao oxigênio e o hidrogênio ao cloro, constituem a mesma lei que inspira a busca da célula Adão à célula Eva; e de que nenhum abismo separa o mundo físico do mundo moral. (Mantegazza, 1898, p.254)

Um mesmo tipo de avanço histórico gradual, idêntico em sua estrutura ao que tinha propiciado o passo progressivo das culturas desde a "selvageria" até a civilização industrial do "homem branco", estava também inscrito no mundo da matéria - na física e na biologia de nossa espécie. O progresso gradual por meio da concorrência ficou assim instalado no imaginário finissecular como o princípio fundamental inquestionável da organização da vida e, em conseqüência, do devir (sócio-)biológico de nossa espécie em todo o planeta.

\section{A LUTA IDEOLÓGICA E METAFÍSICA ENTRE O CRISTIANISMO E O MONISMO CIENTÍFICO SOBRE A ORIGEM DO SER HUMANO}

Por sua vez, o anti-dualismo ou anti-cristianismo do discurso científico sobre a origem do homem tomou um aspecto mais ou menos radical segundo o desejo dos vários autores e seus diferentes graus de compromisso com a metafísica materialista do monismo. De todos os confrontos entre evolucionistas e pensadores cristãos oitocentistas, sem dúvida o mais conhecido é a famosa controvérsia pública entre T. H. Huxley e um conhecido prelado inglês. O interesse popular suscitado por esse confronto direto (previamente anunciado ao público), entre a cosmovisão científica do célebre Huxley e a visão religiosa desse bispo popular, foi imenso:

A expectativa era tremenda. A sala de conferências em que iria ocorrer a discussão mostrou-se demasiado pequena para o público, e a reunião foi transferida para a Biblioteca do Museu, que estava repleta até a asfixia muito antes de os protagonistas subirem ao palco. O número de espectadores esteve entre setecentos e mil. Se o debate ocorresse no período do curso acadêmico, ou se os 
organizadores permitissem a entrada de todo o público, certamente seria impossível acomodar a multidão para ouvir o discurso do bispo audaz ... O bispo chegou com atraso e falou durante meia hora com inimitável energia, injustiça e ausência de conteúdo. O tratamento que dispensava ao assunto deixou evidente que o "engolira" até engasgar-se, e que não sabia nada de primeira mão ... O bispo declarava com exagero retórico que não tinha depoimentos de fato que apoiassem a Darwin ... E continuou ironizando: "Gostaria de perguntar ao professor Huxley, que está a meu lado e disposto a despedaçar-me assim que me sente, sobre sua convicção de que descende de um macaco: 'essa ascendência simiesca lhe vem pela linha de seu avô ou de sua avó?'”12

O impassível Huxley, que a princípio não desejava responder a uma observação tão insolente, decidiu-se finalmente e falou com a habitual mordacidade e com certo desprezo, dirigindo-se firme e serenamente ao pobre religioso: "Não consideraria uma vergonha proceder dessa origem. Mas me envergonharia se descendesse de alguém que tivesse prostituído os dons da cultura e da eloqüência a serviço do preconceito e da falsidade" (citado em Darwin, 1997, p.449-451).

Pois bem, além dessa polêmica tão famosa - e tomando formas que variavam desde pacatas críticas envolvendo a distinção metafísica entre o espírito e a matéria, até furibundas arengas sobre o abandono do vão orgulho de imaginar-nos como criaturas espirituais eleitas por um deus fictício - , a antropologia científica do final do século XIX adquiriu, por vezes, a dimensão de uma autêntica defesa ideológica contra o ópio religioso do Gênesis cristão. Sem dúvida, um dos casos mais extremos envolveu a figura da evolucionista Clémence Royer. ${ }^{13}$ Em 1870, um ano antes da aparição do A origem do homem darwiniano, Royer deu à luz seu famoso Origine de l'homme et des societés. Nessa obra, o decidido anti-cristianismo materialista de Royer - que considerava o pensamento religioso como a manifestação última e mais desenvolvida dos temores instintivos das bestas no ser humano - era explícito e categórico:

$\mathrm{Na}$ base de nossas populações européias há um velho germe de instinto cristão que fermenta. A Bíblia e especialmente o Evangelho, estendidos entre nossas massas por cegos propagandistas, em lugar de constituir para elas uma palavra consoladora e divina, semearam em todos os espíritos os erros que um dia trarão frutos não esperados por quem participou em tão estranho plantio. ${ }^{14}$

Perante os velhos sacerdotes escandalizados pela pretensão evolucionista de nossa descendência a partir de um ancestral bestial, a resposta de Clémence 
se apresentava como um raio científico e racionalista lançado sobre as raízes da ignorância religiosa:

Definitivamente, por que teríamos de gritar com raiva contra um tal antecessor [simiesco]? Se para termos valor devemos clamar com ira por nossa genealogia, será melhor ... pertencer a essa raça cristã que, sob o pretexto de vingar a Deus, fez as cruzadas, os autos-de-fé ... que acendeu fogueiras para os Giordano Bruno, os Jean Huss, os Servet, que meteu na prisão os Campanella, que fez abjurar os Galileu... (Royer, 1990, p.149)

Ernst Haeckel foi outro dos cientistas que expuseram com veemência todo um arsenal de armas retóricas técnicas, próprias das ciências naturais, contra a cosmovisão anticientífica do cristianismo, encarnada de forma paradigmática nas imagens da criação no paraíso e da posterior queda. Esta citação, ainda que longa, expressa com clareza os principais traços ideológicos da metafísica racionalista haeckeliana e do evolucionismo do século XIX no seu combate materialista e progressista contra a velha antropologia cristã:

A maioria das pessoas sente repugnância diante da idéia de uma ascendência simiesca. É bem mais lindo descender de um ser divino, superior. Já desde os tempos mais longínquos a vaidade humana deleitou-se em fazer remontar sua origem até deuses ou semideuses. A Igreja compreendeu esse desejo muito bem e, com sua habitual facilidade para a interpretação, glorificou esse ridículo orgulho como um sentimento de humildade "cristã" ... Na maioria dos sermões que do púlpito ou do altar se lançam contra a marcha triunfal da doutrina evolutiva, dominam o amor-próprio e a vaidade; eis duas fraquezas de caráter que nos legaram os simios ... Nós nos afastamos de tão pueris tolices que o ridículo orgulho nobiliário sustentou desde a Idade Média até nossa época ... A maioria dos homens gosta de remontar sua genealogia a algum barão e, se possível, a algum príncipe famoso, e não a escuros camponeses, e mesmo estes decidem considerar como o primeiro ancestral do gênero humano um Adão que cai no pecado e não um macaco ativo e aperfeiçoável ... Com respeito a mim, prefiro ser a posteridade aperfeiçoada de um ancestral simiesco, elevado através da concorrência pela vida desde o estágio de outros mamíferos inferiores, aos despojos degenerados de um Adão, semelhante a deus, mas degradado pelo pecado; despojos de um "bloco de argila" e de uma Eva "criada" com uma das costelas do tal Adão. (Haeckel, 1877, p.616-617) 
Além dos casos particulares de Huxley, Royer ou Haeckel, podemos dizer que uma das primeiras necessidades do discurso biológico do século XIX sobre a evolução do homem consistiu em enfraquecer a crença generalizada na veracidade mais ou menos literal do relato cristão do Gênesis..$^{15} \mathrm{~A}$ esse respeito, conhecemos a atitude reservada e diplomática de Darwin no momento do embate direto entre o discurso das ciências e a verdade revelada na Bíblia. (Seu funeral foi celebrado sob todo o rito cristão na Abadia de Westminster, onde seus restos descansam a poucos metros dos de Newton). No entanto, na obra de Darwin se encontram claras tentativas de "dessacralizar" a religião, preparando assim o terreno para que a linguagem das ciências biológicas pudesse entrar com plena legitimidade no terreno mítico das origens, até então monopolizado na Europa pela Igreja. ${ }^{16}$ De fato, embora seu tom e seus referentes teóricos sejam diversos, as bases da crítica científica de Darwin à idéia religiosa oferecem várias analogias com a que - quase na mesma época Marx realizava na filosofia política: "O fundamento da crítica irreligiosa é este: o homem faz a religião, a religião não faz o homem. ${ }^{17}$

Em Marx, a crítica irreligiosa se estabelecia para deslegitimar o sistema de dominação capitalista-imperialista contemporâneo, enquanto Darwin a empregou para dar-lhe uma nova legitimação científica. A principal diferença entre as críticas marxista e darwiniana está na definição de uma essência política ou biológica, respectivamente, para esse homem (conceito fantasmagórico) que sempre sonhou com deuses. Para Marx, o homem é o mundo do homem, o Estado, a sociedade. Esse Estado, essa sociedade, produzem a religião, uma consciência do mundo às avessas (cit. em Ricoeur, 1997, p.43). Em Darwin, no entanto, esse mundo do homem corresponde unicamente à biologia humana, que em si mesma podia explicar o progresso das sociedades selvagens dos ancestrais até a civilização burguesa como o apogeu do mundo correto.

Em todo caso, durante as passagens que Darwin dedica - consciente ou inconscientemente - a deslegitimar a aura sagrada do discurso cristão, explica-se o desenvolvimento do sentimento religioso em nossa espécie como o produto natural de uma evolução de certas emoções, suscitadas como "erros instintivos" nos animais "inferiores”. Por si só, a natureza do ser humano promovia o desenvolvimento social da fé religiosa como um temor infantil surgido a partir das emoções instintivas das bestas. A origem da idéia de um agente espiritual oculto podia rastrear-se, para Darwin, em sensações animais 
preconscientes - como as que poderiam surgir na imaginação de um cachorro assustado, ao observar o movimento de objetos pelo vento - que se associavam à expressão do temor diante de agentes desconhecidos e invisíveis. Darwin contribui com alguns exemplos que considerava claramente significativos:

A tendência nos selvagens para imaginar que os objetos e ações naturais estão animados por essências espirituais ou vitais, talvez possa ser ilustrada por um fato inquestionável que certa vez percebi: meu cachorro, um animal sensível e são, estava deitado na grama numa tarde cálida e calma; a pouca distância, uma ligeira brisa movia ocasionalmente um guarda-chuva aberto ... Cada vez que ele se movia ligeiramente, o cachorro rosnava e ladrava. Deve, penso eu, ter raciocinado para si, de uma forma rápida e inconsciente, que esse movimento sem nenhuma causa aparente indicava a presença de algum agente vital estranho, e nenhum estranho tinha direito de entrar em seu território. ${ }^{18}$

Continuando a tarefa de "dessacralização" do discurso religioso em torno das origens da espécie, para Darwin, de fato, podia estabelecer-se uma gradação progressiva insensível entre o sentimento religioso do "selvagem" e as manifestações instintivas dos animais mais elevados na hierarquia natural, como seu próprio cachorrinho. A respeito do temor dos selvagens à ação de agentes espirituais potencialmente benéficos ou maléficos sobre as pessoas, afirmava: "Estas conseqüências indiretas e miseráveis de nossas mais altas faculdades podem ser comparadas com os incidentais e ocasionais erros dos instintos dos animais inferiores" (Darwin, 1871, p.69).

Ainda que Darwin não tenha explicitado o argumento irreligioso com respeito à religião cristã, uma inevitável conclusão laica era óbvia para qualquer leitor inteligente contemporâneo do biólogo inglês. Depois de unir numa seqüência progressiva os medos instintivos do animal com o sentimento religioso do selvagem, o passo seguinte no raciocínio gradualista de Darwin deveria ser uma vinculação dessa religiosidade primitiva com as formas mais desenvolvidas da religiosidade humana, como a própria fé cristã. Desconstruindo a idéia religiosa - embora de maneira tácita no caso peculiar do cristianismo - como o resultado final de uma série progressiva de instintos animais inconscientes, a biologia darwiniana tentava (e conseguiu) ganhar posições ao discurso da Igreja no espaço simbólico das narrações sobre a aparição de nossa espécie. 


\section{Conclusões}

Durante o século XIX, os povos de Ocidente sofreram uma profunda transformação no imaginário científico sobre o surgimento da humanidade. O evolucionismo oitocentista, ao falar das origens da vida e do ser humano, entrou plenamente no terreno do conhecimento que, tradicionalmente, em todos os povos, tinha sido patrimônio exclusivo do mito e da religião. Refirome ao espaço simbólico do sagrado. Este aparece em todas as sociedades humanas como um componente inquestionável do imaginário coletivo; corresponde ao sagrado tudo o que não pode pôr-se em dúvida de maneira alguma. Dentro dessa parcela do incontestável, todas as sociedades reservam um espaço para explicar sua própria origem: é assim que fica circunscrito, em todas as culturas, o terreno dos mitos fundacionais.

Neste trabalho busquei apresentar alguns aspectos metafísicos e ideológicos do debate que se estabeleceu entre o cristianismo e a biologia evolutiva da época, assim como mostrar a importância desses elementos dentro do paradigma darwiniano de fins do século XIX. Debate que afinal conduziu a uma mudança muito profunda no discurso das sociedades ocidentais sobre as origens e sobre o lugar de nossa espécie na natureza. Tanto na luta estabelecida entre os evolucionistas seguidores da filosofia monista contra as narrativas cristãs sobre a criação, como na própria crítica que Darwin realiza à religião em termos naturalistas, encontram-se numerosos elementos ideológicos e metafísicos como componentes essenciais do primeiro darwinismo. Longe das visões eufóricas da filosofia e da historiografia do evolucionismo de cunho positivista, esta análise histórica parece consistente com a idéia de que o evolucionismo darwiniano, como paradigma cientifico emergente no final do século XIX, teve que enfrentar toda uma série de elementos ideológicos e metafísicos - além dos puramente empíricos - como componentes inseparáveis dos seus argumentos propriamente naturalísticos para, finalmente, conseguir se impor, nas sociedades ocidentais oitocentistas, sobre a metafísica cristã exposta no velho relato do Gênesis.

\section{NOTAS}

${ }^{1}$ Este trabalho foi possível graças a uma Bolsa da AECI/Ministerio Español de Asuntos Esteriores (Programa II/B). O autor é doutor em Biologia pela Universidad Autónoma de Madrid e Pesquisador Visitante no Grupo de Pesquisa em História, Filosofia e Ensino de Ciências Biológicas, Instituto de Biologia, da Universidade Federal da Bahia (UFBA). Pu- 
blicou La razón salvaje: la lógica del dominio - tecnociencia, racismo y racionalidad (Madrid: Lengua de Trapo, 2007), que recebeu o V Premio Nacional de Ensayo Caja Madrid 2007, assim como numerosos artigos sobre história e filosofia da ciência.

${ }^{2} \mathrm{Na}$ realidade, esse processo já havia começado séculos atrás, ainda que em escala menor. Cf. SHAPIN, Steven. La revolución científica: una interpretación alternativa. Buenos Aires: Paidos Studio, 2000.

${ }^{3}$ Cf. HABERMAS, Jürgen. Ciencia y técnica como "ideología". Madrid: Tecnos, 1999; BLOOR, David. Conocimiento e imaginario social. Barcelona: Gedisa, 2003.

${ }^{4}$ LYELL, Sir Charles. Geological evidences of the antiquity of man: with remarks on theories of the origin of species by variation. London: Murray, 1863.

${ }^{5}$ Em 1900, os paleoantropólogos já estimavam a antiguidade da espécie humana em 1,2 milhão de anos. Cf. RÉMOND, M. Douze cent mille ans d'humanité et l'âge de la Terre. In: CONGRĖS INTERNATIONALE D'ANTHROPOLOGIE ET D'ARCHEOLOGIE PRÉHISTORIQUES. Compte Rendu de la douzième session à Paris. Paris: Masson et Cie. Editeurs, libraires de l'Académie de Médecine, 1900. p.49-51.

${ }^{6}$ VOGT, Carl. Leçons sur l'Homme. Sa place dans la création et dans l'histoire de la terre. Trad. de J. Moulinié. Paris : Ch. Reinwald et Cie, (1.ed. 1868), 1873.

${ }^{7}$ HAECKEL, Ernest. Anthropogénie ou Histoire de l'Évolution Humaine. Leçons familières sur les principes de l'Émbryologie et de la Phylogénie humaines. Trad. da 2.ed. alemã por Ch. Letorneau. Paris: Reinwald et Cie, 1877.

${ }^{8}$ BÜCHNER, Louis. L'Homme selon la Science. Son passé, son présent, son avenir, ou D'où venons-nous? Qui sommes-nous? Où allons-nous? Trad. do alemão por Ch. Letourneau. Paris: C. Reinwald et Cie., 1872.

${ }^{9}$ HUXLEY, Thomas Henry. The interpreters of Genesis and the interpreters of Nature. Reprod. em HUXLEY. Collected Essays. Olms: Hildesheim, 1970. 9v. v.IV (1885), p.139163.

${ }^{10}$ SPENCER, Herbert, Principes of biology. 2v. London: Williams and Norgate, 1864; SPENCER, Herbert. The principles of psicology. $2 \mathrm{v}$. London: Williams and Norgate, 18701872.

${ }^{11}$ MANTEGAZZA, Paolo. L'evoluzione regresiva. Archivio per l'antropologia e la Etnologia, v.28, 1898, p.243-254. p.253.

${ }^{12}$ Reproduzido em DARWIN, Charles, Autobiografía y cartas escogidas. Madrid: Alianza, 1997. p.449-451. O próprio Huxley, numa carta escrita a Francis Darwin, fala-nos assim de sua demolidora resposta ao prelado: "O bispo começou seu discurso, e com grande surpresa minha demonstrou muito cedo que era tão ignorante que não sabia defender sua própria causa. Eu ia me animando à medida que ele falava, e quando se voltou para mim com sua pergunta insolente, disse baixinho a Sir Benjamin, 'O Senhor o pôs em minhas mãos'.'. DARWIN, 1997, p.453-454.

${ }^{13}$ Combativa evolucionista e primeira tradutora de Darwin ao francês. Foi, ademais, a úni- 
ca mulher que no século XIX participou ativamente em diversos Congressos Internacionais de Antropologia Pré-histórica.

${ }^{14}$ ROYER, Clemence. Origine de l'Homme et des sociétés. Reimpr. da ed. de Guillaumin et Cie, Paris, 1870. Cahiers de Gradhiva, 17. Bibliothèque du Musée de l'Homme, 1990. p.587.

${ }^{15}$ Um magnífico estudo sobre as relações oitocentistas entre ciência (especialmente, a paleontologia) e crença na Península Ibérica e nos países latino-americanos se encontra em PELAYO, Francisco. Ciencia y creencia en España durante el siglo XIX. Tese (Doutorado) - Universidade Complutense. Madrid, 1988.

${ }^{16}$ Sobre esse assunto, é interessante - apesar de seu darwinismo - o ensaio do darwinista TORT, Patrick. Darwin y la laicización del discurso sobre el hombre. Asclepio, Madrid: CSIC, v.LII, n.2, p.51-85, 2000.

${ }^{17}$ MARX, K. Contribution a la critique du droit de Hegel, Paris : Autier, 1971. Citado em RICOEUR, Paul. L'ideologie et l'utopie. Paris: Ed. du Seuil, 1997. p.43.

${ }^{18}$ DARWIN, Charles. The descent of man, and selection in relation to sex. $2 \mathrm{v}$. London: John Murray, 1871. v.I, p.67.

Artigo recebido em março de 2008. Aprovado em setembro de 2008. 